\title{
SYNTHESIS OF SOME SUBSTITUTED SCHIFF BASES BY
}

\section{MICROWAVE IRRADIATON: A STEP TO ECO-FRIENDLY SYNTHESIS}

\section{P. Bodade, Y. K. Meshram}

Department of Chemistry,G.S.College of science,arts and commerce, Khamgaon,Buldhana, Maharashtra- India Corresponding author Email:yuvrajmeshram@yahoo.com

\begin{abstract}
Schiff bases are synthesized by different methods by the condensation between primary amines and aldehyde or ketones. From literature survey, it was cleared that many work on Schiff bases is going on. But each work is only concerns with conventional method and grinding method. But very few reports were observed on synthesis of Schiff bases by green approach. Therefore, in present work some substituted Schiff bases are prepared from primary amines and substituted aromatic aldehydes.

Synthesis of some substituted Schiff bases have been reported by microwave irradiation methods.
\end{abstract}

Keywords - Schiff bases ,Aromatic aldehydes, Microwave irradiation

\section{Introduction}

A Schiff base is a nitrogen analog of an aldehyde or ketone in which the $\mathrm{C}=\mathrm{O}$ group is replaced by $\mathrm{RC}=\mathrm{N}$ group. It is usually formed by condensation of an aldehyde or ketone with a primary amine. Schiff bases have a large number of synthetic uses in organic chemistry. The research on the chemistry of Schiff bases has been a focus of attention for chemists for several years; due to their wide spread diversified biological activities. Schiff bases, also known as azomethines due to they have $\mathrm{RC}=\mathrm{N}$ group, play important roles in biological systems.

They are facing a growing interest due to their various applications, e.g. as insecticidal 1, antibacterial 2, antituberculosis ${ }^{3}$, antimicrobial 4, anticonvulsant ${ }^{5}$, antifeedant ${ }^{6}$ etc.

In view of these facts we can clear about that Schiff base are important not only in medical chemistry, but also in organic synthetic chemistry. Schiff base perhaps are synthesized in various method. 
In the last few years Microwave -induced Organic Reaction has gained popularity as a non-conventional technique for rapid organic synthesis ${ }^{7}$. Microwave-assisted synthesis has a large impact on synthetic organic chemistry, particulary in medicinal/combinatorial chemistry.

Most organic reactions have been heated using traditional heat transfer equipment such as oil baths, sand baths and heating jackets. These heating techniques are rather slow, and a temperature gradient is created within the sample.

In contrast in microwave dielectric heating the microwave energy is introduced into chemical reactor remotely and direct access by energy source to reaction vessel is obtained.

\section{REVIEV OF LITERATURE}

Bond , Howard, W. et al., (1955) have synthesized a series of Schiff bases from amino nucleoside. These compounds were evaluated for antiamoebic activity. Only the vanillin and ethyl vanillin derivatives showed any activity.

Biradar, N.S.et al., (1977) have prepared Schiff base from salicyaldehyde and aniline, $\mathrm{p}$-toluidine, $\mathrm{p}$-chloroaniline and $\mathrm{p}$-anisidine in order to synthesise silicon adducts. 8

General account of summary of reaction of aldehyde with amines (aromatic or aliphatic)has been reviewed by Murray.

A new one pot procedure for generation of azomethine via chromium salt has been investigated by Anderson and co workers.

Yang etal have synthesized salicylaldimine by microwave irradiation technique.

Oza, Haresh. et al.,(1998) have synthesized thirty novel thiazolidinone (1) derivatives as potential anti-tubercular agents. $\mathrm{R}=\mathrm{Ph}, \mathrm{ClC}_{6} \mathrm{H}_{4}, \quad$ 4$\mathrm{Me}_{2} \mathrm{NC}_{6} \mathrm{H}_{4}, \mathrm{NO}_{2} \mathrm{C}_{6} \mathrm{H}_{4}, \mathrm{PhCH}: \mathrm{CH}$, etc, $\left.; \mathrm{R} 1=\mathrm{H}, \mathrm{Me}\right)$ by cyclocondensation with thioglycollic acid and thiolactic acid. The compounds were screened for their anti-tubercular activity against Mycobacterium tuberculosis. ${ }^{9}$ 
Gong, Qiao-Juan et al., (2000) have prepared five Schiff bases using substituted benzaldehyde and 4 -amino antipyrine. It was found that the fluorescence intensities of the compounds at optimum $\mathrm{pH}$ values were 16 to 319 times as much as that of aminoantipyrine. 10

Shetty et al., (2004) have synthesized and evaluated the antibacterial activity of thirty Schiff bases synthesized from 2-amino-3-(Nchlorophenyl carboxamido)-4.5- dimethylthiophenes. The Schiff bases were prepared by condensing this compound with ten different aldehydes. $\left(\mathrm{R}=\mathrm{XC}_{6} \mathrm{H}_{4},=2-\mathrm{Cl}, 4-\mathrm{Cl}, 2-\mathrm{OH}, 2-\mathrm{NO}_{2}, 3-\mathrm{NO}_{2}, 4-\mathrm{Me}, 4-\mathrm{MeO}, 4-\right.$ $\mathrm{Me}_{2} \mathrm{~N}, 3,4-(\mathrm{MeO})_{2}-\mathrm{C} 6 \mathrm{H} 3,3,4,5-(\mathrm{MeO}) 3 \mathrm{C}_{6} \mathrm{H}_{2} \cdot{ }^{11}$

Naik, Bhanvesh, D., et al., (2004) have synthesized some heterocyclic Schiff bases by treating 2-amino - 4- (couraminyl-3) thiazole with different aldehydes and then treating the compounds with chloroacetylchloride.The compounds were screened for their antibacterial activity. ${ }^{12}$.

Many researchers have reported the synthetic utility of microwave irradiation in routine organic synthesis 13,14. Compared to traditional processing of organic synthesis, microwave-enhanced chemistry saves significant time and very often improves conversions, clean product formation.

It can be termed as 'e-chemistry' because it is easy, effective, economical and eco-friendly and is believed to be a step towards green chemistry. Further, it offers low cost with simplicity in processing and handling 15. By this method, one can also develop new reaction conditions.

In 1986, Gedye and co-workers first reported the utilization and advantages of microwave irradiation for organic synthesis 16,17 and studied different types of reactions . Later on, this technique has been used to promote a variety of chemical reactions such as additions, cycloadditions, substitutions, eliminations, fragmentations etc ${ }^{18-24}$ 


\section{METHOD AND MATERIAL:}

\section{Typical experimental procedure:-}

\section{3,4,5trihydroxy-benzohydrazide:}

3, 4,5-trihyydroxy benzohydrazide was synthesized by refluxing propyl gallete $(0.01 \mathrm{~mol})$ and hydrazine hydrate in presence of $25 \mathrm{~cm} 3$ ethanol for about 6 hrs. While refluxing 2-3 drops of conc. H2SO4 was added .After refluxing the crude compound was filtered and washed with distilled water .It was then recrystallized from ethanol. This compound is further used for the synthesis of substituted Schiff bases.

Following compounds are synthesized by microwave irradiation method.

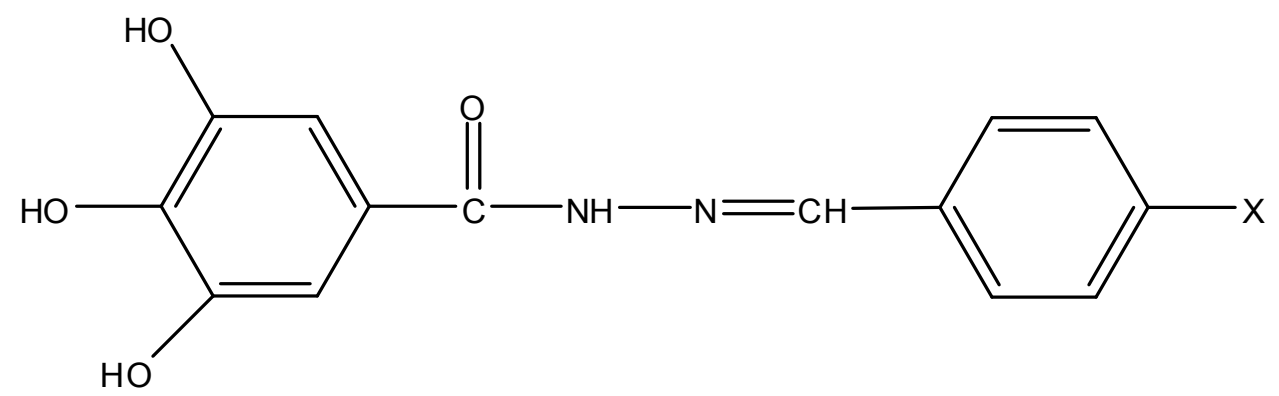

$$
\mathrm{X}=\mathrm{NO}_{2}, \mathrm{Cl}, \mathrm{Br}, \mathrm{F}, \mathrm{I}, \mathrm{CH}_{3}, \mathrm{OCH}_{3}, \mathrm{OH}
$$

\section{3,4,5trihydroxy benzoamido-4-methylimine.}

0.01 mol.3,4,5 trihydrox y benzohydrazide was mixed with equimolar amount of $\mathrm{p}$-methyl benzaldehyde. In this reaction mixture Dimethyl sulphoxide was added as solvent .It was then irradiated to microwave. After completion of reaction, the crude product was washed with distilled water, and recrystallized from ethanol.

IR:( $v \quad \max ) \quad \mathrm{cm}^{-1}: \quad 3420(\mathrm{OH}), \quad 1617.72(\mathrm{C}=\mathrm{N}), \quad 1563,1484.13 \quad(\mathrm{C}=\mathrm{C}$ Aromatic), 1400(-CH3) 
$1 \mathrm{H} \quad \mathrm{NMR}(\delta, \quad \mathrm{ppm}): \quad \delta 2.15(\mathrm{~s}, 3 \mathrm{H}, \mathrm{sp} 3 \quad-\mathrm{CH} 3), \quad \delta 3.3 \quad(\mathrm{~s}, 2 \mathrm{H},-\mathrm{OH})$, $\delta 7.82(\mathrm{~s}, 1 \mathrm{H}, \mathrm{Ar}) . \delta 8.2(\mathrm{~s}, 1 \mathrm{H}, \mathrm{CH}=\mathrm{N})$

Yield :82\%,time required for completion of reaction:40 sec.

\section{3,4,5trihydroxy benzoamido-4-nitroimine.}

0.01 mol.3,4,5 trihydrox y benzohydrazide was mixed with equimolar amount of p-nitro benzaldehyde. In this reaction mixture Dimethyl sulphoxide was added as solvent .It was then irradiated to microwave. After completion of reaction, the crude product was washed with distilled water , and recrystallized from ethanol.

IR: $(v \quad \max ) \quad c m-1: \quad 3420(\mathrm{OH}), \quad 1596.19(\mathrm{C}=\mathrm{N}), \quad 1522, \quad(\mathrm{C}=\mathrm{C}$ Aromatic), 1289.7(NO2),842.5(p sub)

$1 \mathrm{H} \operatorname{NMR}(\delta, \mathrm{ppm}): \delta 2.32(\mathrm{~s}, 1 \mathrm{H}, \mathrm{CH} 3), \delta 7.21(\mathrm{~s}, 1 \mathrm{H},-\mathrm{C}=\mathrm{O}), \delta 7.25(\mathrm{~d}, 1 \mathrm{H}, \mathrm{ArH})$, $\delta 7.38(\mathrm{~d}, 1 \mathrm{H}, \mathrm{ArH})$ 68.95(s, $1 \mathrm{H}, \mathrm{CH}=\mathrm{N})$

Yield :67\%,time required for completion of reaction:51 sec.

\section{3,4,5trihydroxy benzoamido-4-hydroxyimine}

0.01 mol.3,4,5 trihydroxy benzohydrazide was mixed with equimolar amount of $\mathrm{p}$-hydroxy benzaldehyde. In this reaction mixture Dimethyl sulphoxide was added as solvent .It was then irradiated to microwave. After completion of reaction, the crude product was washed with distilled water, and recrystallized from ethanol.

IR:( $v$ max $) \quad c m-1: \quad 3190(\mathrm{OH}), \quad 1605(\mathrm{C}=\mathrm{N}), \quad 1585, \quad 1560,1525 \quad(\mathrm{C}=\mathrm{C}$ Aromatic), $1 \mathrm{H}$

$\operatorname{NMR}(\delta, \mathrm{ppm}): \delta 3.5(\mathrm{~s}, 2 \mathrm{H},-\mathrm{OH}), \delta 7.68(\mathrm{~d}, 1 \mathrm{H},-\mathrm{Ar}), \delta 8.21(\mathrm{~s}, 1 \mathrm{H}, \mathrm{CH}=\mathrm{N})$.

Yield :78\%,time required for completion of reaction:44 sec.

\section{3,4,5trihydroxy benzoamido-4-chloroimine.}

0.01 mol.3,4,5 trihydroxy benzohydrazide was mixed with equimolar amount of p-chloro benzaldehyde. In this reaction mixture Dimethyl sulphoxide was added as solvent .It was then irradiated to microwave. After completion of reaction, the crude product was washed with distilled water, and recrystallized from ethanol. 
IR:( $v \quad \max ) \quad c m-1: \quad 3045(\mathrm{OH}), \quad 1622.18(\mathrm{C}=\mathrm{N}), \quad 1588.8,1484 \quad(\mathrm{C}=\mathrm{C}$ Aromatic),819.6(p sub. Cl)

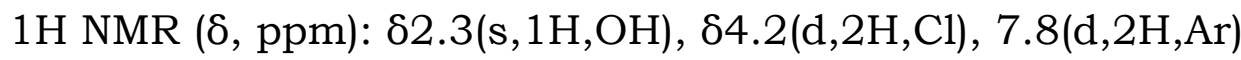

$\mathrm{S} \delta 8.1(\mathrm{~d}, 1 \mathrm{H}, \mathrm{CH}=\mathrm{N})$

Yield :69\%,time required for completion of reaction:51 sec.

\section{3,4,5trihydroxy benzoamido-4bromoimine.}

0.01 mol.3,4,5 trihydroxy benzohydrazide was mixed with equimolar amount of p-bromo benzaldehyde. In this reaction mixture Dimethyl sulphoxide was added as solvent .It was then irradiated to microwave. After completion of reaction, the crude product was washed with distilled water, and recrystallized from ethanol.

IR:( $v \quad \max ) \quad c m-1: \quad 3422(\mathrm{OH}), \quad 1623.8(\mathrm{C}=\mathrm{N}), \quad 1583,1481 \quad(\mathrm{C}=\mathrm{C}$ Aromatic),699.9(Br)

$1 \mathrm{H}$ NMR ( $\delta, \mathrm{ppm}): \delta 2.5(\mathrm{~m}, 4 \mathrm{H}-\mathrm{OH}), \delta 4.8(\mathrm{~s}, 1 \mathrm{H}, \mathrm{Br}), \delta 7.50(\mathrm{~s}, 1 \mathrm{H}, \mathrm{Ar})$

$\delta 8.78(\mathrm{~s}, 1 \mathrm{H} . \mathrm{C}=\mathrm{N})$.

Yield :80\%,time required for completion of reaction: $1 \mathrm{~min} .02 \mathrm{sec}$

\section{3,4,5trihydroxy benzoamido-4-fluoroimine.}

0.01 mol.3,4,5 trihydroxy benzohydrazide was mixed with equimolar amount of $\mathrm{p}$-fluoro benzaldehyde. In this reaction mixture Dimethyl sulphoxide was added as solvent .It was then irradiated to microwave. After completion of reaction, the crude product was washed with distilled water, and recrystallized from ethanol.

IR:(v max) cm-1: 3400(OH), 1630(C=N), 1506 (C=C Aromatic), 1153.7(-fl)

$1 \mathrm{H} \operatorname{NMR}(\delta, \mathrm{ppm}): \delta 2.35(\mathrm{~s} 1 \mathrm{H},-\mathrm{OH}), \delta 7.28(\mathrm{~s}, 1 \mathrm{H}, \mathrm{Ar}),. \delta 8.22(\mathrm{~d}, 2 \mathrm{H}, \mathrm{C}=\mathrm{N})$, .

Yield :77\%,time required for completion of reaction:45 sec

\section{3,4,5trihydroxy benzoamido-4-methoxylimine.}

0.01 mol.3,4,5 trihydroxy benzohydrazide was mixed with equimolar amount of $\mathrm{p}$-methoxy benzaldehyde. In this reaction mixture Dimethyl sulphoxide was added as solvent .It was then irradiated to microwave. After completion of reaction, the crude product was washed with distilled water, and recrystallized from ethanol. 
IR:(v max) cm-1: $3305(\mathrm{OH}), \quad 1618(\mathrm{C}=\mathrm{N}), \quad 1595, \quad 1570,1520 \quad(\mathrm{C}=\mathrm{C}$ Aromatic),

$1 \mathrm{H} \operatorname{NMR}(\delta, \mathrm{ppm}): \delta 2.05(\mathrm{~s}, 1 \mathrm{H}, \mathrm{OH}), \quad 67.44(\mathrm{~s}, 1 \mathrm{H}, \mathrm{Ar}) \delta 8.95(\mathrm{~s}, 2 \mathrm{H}, \mathrm{C}=\mathrm{N})$.

Yield :71\%,time required for completion of reaction:56 sec

\section{3,4,5trihydroxy benzoamido-4-iodoimine.}

0.01 mol.3,4,5 trihydroxy benzohydrazide was mixed with equimolar amount of p-iodo benzaldehyde. In this reaction mixture Dimethyl sulphoxide was added as solvent .It was then irradiated to microwave. After completion of reaction, the crude product was washed with distilled water , and recrystallized from ethanol.

IR:(v max) cm-1: 3447(OH), $1617(\mathrm{C}=\mathrm{N}), 1576,1549$ (C=C Aromatic), 620.5(-I)

$1 \mathrm{H} \operatorname{NMR}(\delta, \mathrm{ppm}): 24.05(\mathrm{~s}, 3 \mathrm{H}, \mathrm{OH}), 87.28(\mathrm{~s}, 1 \mathrm{H}, \mathrm{Ar}-\mathrm{H})$

Yield :75\%,time required for completion of reaction:50 sec

\section{Result and Discussion:}

It is very suit for industrial manufacture which consumes the least time to finish the synthesis of Schiff base. Microwave irradiation synthesis is not only use the least time, but also has the greatest yield. Microwave irradiation is becoming an increasingly popular method of heating which replaces the classical one because it proves to be a clean, cheap, and convenient method. Often, it affords higher yields and results in shorter reaction time. This method of heating has been extended to almost all areas of organic chemistry.

\section{Conclusion}

In summary, we have developed a simple, efficient and more eco-friendly method for synthesis of substituted Schiff bases by using microwave irradiation technique. The main advantages of this procedure are simple and convenient, and time consuming, 


\section{References:}

S.S.Murthy,A. Kaur, B. Sreenivasalu, R.N. Sarma, (1998) Indian J. Exp.Biol.,36, 724

K.N. Venugopala and V.A.Jayashree, (2009) Indian J. Pharm.Sci. 70,88.

N. Solak and S. Rollas, (2006) ARKIVOC, xii 173.

S.J. Wadher, M.P. Puranik, N.A.Karande and P.G.Yeole, (2009) Int.J. Pharm Tech Res., 1, 22.

M. Verma, S.N.Pandeya, K.N.Singh and J.P.Stables, (2004) Acta Pharm., 54.

S.S. Murthy, A. Kaur, B. Sreenivasulu and P.N. Sarma, (1998) Indian J. Exp. Biol., 36:724

Bond, Howard, W.; Sherman, John F.; Taylor, D. Jane. (1954-1955) U.S. Department of Health, Education and Welfare, Bethseda, MD, Antibiotics Ann (1955) volume date, 2751-6.

Biradar, N.S.; Hosmane, N.S. (1977) Department of Chemistry, Karnatak University, Dharwar, India. Indian Journal of Chemistry, Section A: Inorganic, Physical, Theoretical \& Analytical, 15A (7) 659-60.

Oza, Haresh; Joshi Dharti; Parekh, Hansa. (1998) Department of Chemistry, Saurashtra University. Rajkot, India, Indian Journal of Chemistry, Section B Organic Chemistry Including Medicinal Chemistry, 37B, (8), 822-824.

Gong, Qiao - Juan; Jin , Wei - Jun; Dong, Chuan; Liu, Chang- Song. (2000) Department of Chemistry, Shanxi University,Taiyuan, People's Republic of China.Yingyong Huaxue, 17(2), 227-229.

Shetty, K.S. Manjunatha; Somashekar, Vanitha; Mohan, S. M.S. Ramiah, (2004) Drugs and Allied Products Testing Laboratory, India, Asian Journal of Chemistry, 16(2), 623-627. 
Naik, Bhanvesh, D.; Desai, K.R. (2004) South Gujarat University, India. Asian Journal of Chemistry, 16(3-4), 1749-1752.

Borah, R., Kalita, D. J., and Sarma , J. C., 2002, Indian J. Chem.; 41B, 1032.

Kidwai, M., Dave, B., and Venkataramanan, R., 2002, Indian J. Chem.; $41 \mathrm{~B}, 2414$.

Hayes, B. L., 2002, Microwave Synthesis: Chemistry at the Speed of Light; CEM Publishing: Matthews, NC.

Gedye, R., Smith, F., Westaway, K., Ali, H., and Baldisera, L., 1986, Tetrahedron Lett., 27, 279.

Gedye, R., Smith, F., Westaway, K., Ali, H., and Baldisera, L., 1987, Can. J. Chem., 66, 17.

Caddick, S., 1995, Tetrahedron; 51,10403.

A. Acosta, P. de la Cruz, P. De Miguel, E. Diez-Barra, A. de la Hoz, F. Langa, A. Loupy, M. Majdoub, N. Martín, C. Sanchez and C. Seoane; (1995) Tetrahedron Letters; 36, 2165.

Sena, V. L. M., Srivastava, R. M., Oliveira, S. P., and Lima, V. L. M., 2001, Bio. Med. Chem. Letters, 11, 2671.

Shaabani ,A., and Bazgir, A., 2004, Tetrahedron Letters, 45, 2575.

Malhotra, P., Pattan, S., Nikalje, A. P., 2010, Int. J. Pharma. Pharma. Sci., 2 , pp. 21.

Gorobets, N. Yu., Yousefi, B. H., Belaj, F., and Kappe, C. O., 2004, Tetrahedron, 60, 8633.

Simoni, D., Rossi, M., Rondanin, R., Baruchello, R., Grisolia, G., Eleopra, M., Giovannini, R., Bozzoli, A., Davalli, S., Di Fabio, R., and Donati, D., 2005, Tetrahedron Lett., 46, 759. 